\title{
A Review of Chemotherapy for Locally Advanced Head and Neck Cancers
}

\author{
Mohammad Shabani ${ }^{1}$; Mohammad Hassan Larizadeh ${ }^{2, *}$ \\ ${ }^{1}$ Neuroscience Research Center, Neuropharmacology Institute, Kerman University of Medical Sciences, Kerman, IR Iran \\ ${ }^{2}$ Research Center for Health Management Services, Kerman University of Medical Sciences, Kerman, IR Iran \\ *Corresponding author: Mohammad Hassan Larizadeh, Research Center for Health Management Services, Kerman University of Medical Sciences, P. O. Box: \\ 76198 -13159, Kerman, IR Iran. Tel: + 98-9133978116, Fax: + 98-3412264198, E-mail: larizad_mh@yahoo.com
}

Received: November 28, 2013; Revised: December 16, 2015; Accepted: December 28, 2015

\begin{abstract}
Context: Chemoradiation provides a survival advantage as well as increased rate of organ preservation compared with radiation alone in locally advanced head and neck squamous cell carcinoma (LAHNSCC).

Evidence Acquisition: Combined modality protocols can be used in 3 forms: a) induction chemotherapy or neoadjuvant therapy before definitive surgery or radiotherapy, b) Concurrent chemo- radiotherapy, and c) sequential therapy consisting of induction chemotherapy followed by concurrent chemo radiation.

Results: Despite an improvement in organ preservation, induction treatment has no impact on survival. Ongoing phase III trials comparing sequential therapy with concurrent chemoradiation may establish which of these two approaches is superior.

Conclusions: Until those trials have been completed, Taxane- based sequentional therapy can be a reasonable alternative to concurrent chemo radiotherapy in the patients with locally advanced disease.
\end{abstract}

Keywords: Radiotherapy; Head and Neck Neoplasms; Chemotherapy

\section{Context}

Head and neck squamous cell carcinoma (HNSCC) comprise $3-5 \%$ of total cancers and more than $60 \%$ of patients refer at the advanced stage (1). Conventional treatment plan for Loco-regional advanced cancers is surgery followed by adjuvant radiotherapy. In cases who refuse surgery or not fit for the procedure radiotherapy is used as definitive treatment.

Despite the current advances in local treatment of $\mathrm{HN}$ SCC, prognosis of these patients is very poor. About 50 - $60 \%$ of patients with locally advanced head and neck squamous cell carcinoma experience a local recurrence and up to $30 \%$ of them will have metastasis within two years of initial treatment (2-4). In the current decade, a trend has been made for adding chemotherapy to the conventional treatment to improve survival, reduce metastasis (5-7) and to increase organ preservation $(8,9)$. Extensive studies have been performed to evaluate the impact of chemotherapy in treatment of HNSCC. Most of these studies have focused on the cancers of larynx, hypopharynx, oropharynx, and oral cavity (10-12). Chemotherapy is used in three different settings: induction or neoadjuant therapy, concomitant chemo-radiotherapy, and sequential treatment which consists induction Che- motherapy followed by concomitant chemo-radiotherapy (13). In this review, we will present the major findings of the articles evaluating efficacy of these three forms of chemotherapy for the treatment of LAHNSCC

\section{Evidence Acquisition}

\subsection{Induction (Neoadjuvant) Chemotherapy Ran- domized Clinical Trials (RCT's)}

The earlier studies regarding efficacy of chemotherapy in head and neck cancer goes back to 1970's. The first lunched chemotherapy regimen for HNSCC was consisted of $100 \mathrm{mg} / \mathrm{m}^{2}$ cisplatin at the first day followed by continuous infusion of 5 -FU $\left(1000 \mathrm{mg} / \mathrm{m}^{2}\right)$ for 5 consecutive days (PF) (14-16). Induction chemotherapy has been prescribed for preserving organs and also increasing survival rate (17-21).

\subsubsection{Impact of Induction Chemotherapy on Survival Rate in LAHNSCC}

Table 1 shows the results of 8 RCT's which studied the effect of induction chemotherapy on survival rate $(6,7$,

Copyright (C) 2015, Iranian Society of Clinical Oncology. This is an open-access article distributed under the terms of the Creative Commons Attribution-Non Commercial 4.0 International License (http://creativecommons.org/licenses/by-nc/4.0/) which permits copy and redistribute the material just in noncommercial usages, provided the original work is properly cited. 
22-27). Only 2 out of 8 studies have showed the efficacy of induction chemotherapy on improvement of overall survival and the other 6 studies showed no significant improvement. In a phase III RCT by Paccagnella et al. LAHNSCC patients were assigned to loco regional treatment (including radical radiotherapy and/or surgery followed by adjuvant radiotherapy for non-operable and operable disease, respectively) with or without induction chemotherapy. In patients with operable tumor, chemotherapy reduced metastasis but had no effect on survival rate while in non-operable patients, chemotherapy improved survival rate besides reducing metastasis (5-year surveillance: $21 \%$ vs. $8 \%$ ) (7).

In another study (GETTEC Trial), 318 oropharyngeal squamous cell carcinoma were assigned to chemotherapy with cisplatin (10 mg/m² day 1 ) and 5-FU $1000 \mathrm{mg} / \mathrm{m}^{2}$ day 1 - 5 via continuous 24 hours infusion) followed by locoregional treatment (surgery and radiotherapy or radiotherapy alone) or locoregional treatment without chemotherapy. Patients receiving chemotherapy showed improved median survival rate (5.1 years vs. 3.3 years $P=0.03)(6)$.

\subsubsection{Impact of Induction Chemotherapy on Organ Pres- ervation in LAHNSCC}

Two major studies assessing the role of chemotherapy in organ preservation has been published; which evaluated the role of induction chemotherapy for organ preservation in advanced laryngeal and hypopharyngeal primaries.

The leading study for organ preservation in head and neck scc was published at 1995 by Ann Arbor Veterans Affairs Medical Center in New England Journal of Medicine (4). They evaluated the effect of induction chemotherapy on larynx preservation in stage III and IV laryngeal cancers who were candidate for total layrngectomy. In this Phase III randomized trial 332 patients with squamous cell carcinoma of larynx were assigned to chemotherapy followed by definitive radiotherapy or surgery followed by adjuvant radiotherapy. Patients with less than partial response after two cycles of induction chemotherapy (cisplatin day 1 and 5FU day 1 5) underwent salvage surgery. Larynx was preserved in $64 \%$ of patients in chemotherapy group after a median follow up of 33 months. Two-year survival rate was not different between two groups (68\%) (4).

The second study was conducted by European Organization for Research and Treatment of Cancer (EORTC) (8). In this study, 450 resectable advanced laryngeal (tumor stage T3 and T4) or hypo pharyngeal SCC who were candidate for total laryngectomy were assigned to sequential or alternating arm. In sequential arm, patients with $50 \%$ or more reduction of tumor size after 2 cycles of cisplatin plus 5FU received two another cycles followed by definitive conventional radiotherapy and all non-responders $\mathrm{u}$. Patients in alternating arm received four cycles of cisplatin plus 5FU (5FU dose lower than sequential arm) at weeks $1,4,7,10$, and 60 Gray radiation was administered between cycle in three divided $20 \mathrm{~Gy}$ doses. All non-responder after two cycles of chemotherapy and after 50 Gy of radiation in sequential and alternating arms respectively underwent total laryngectomy. There was no significant difference in overall survival between groups and larynx was preserved in $42 \%$ of patients.

\subsection{Concurrent Radiotherapy/Chemotherapy (Chemoradiation)}

Despite the positive results obtained from induction chemotherapy studies regarding organ preservation, the need for a better modality to improve the regional control of the tumor and achieving better results still remained. The risk of local recurrence was still high in operable patients undergoing induction chemotherapy (1). This resulted to consideration of induction chemotherapy with PF as an alternative and not a standard regimen in advanced cancers (especially in cases which organ preservation is of critical importance) (28).

Second generation of studies used concurrent chemoradiation and sequential treatments (29-41). Table 2 shows studies that comparing the results of radiotherapy vs. concurrent chemoradiation (5, 29, 42-46). Improved local control and survival rate is observed in concurrent chemoradiation compared to radiotherapy alone. Results of a phase III clinical trial was published by Calais et al. in 1999, which showed improved 3 year overall survival benefit for patients with advanced oropharyngeal cancers. 226 patients were randomly allocated into two groups: one receiving radiotherapy alone and the other receiving concurrent chemo radiation. Chemotherapy comprised of carboplatin $(70 \mathrm{mg} /$ $\mathrm{m}^{2}$ per day) and 5-FU (600 $\mathrm{mg} / \mathrm{m}^{2}$ per day) using continuous intravenous infusion for three 4 days cycles during radiotherapy. In the concurrent chemo radiation arm, three-year overall survival rate (51\% vs. $31 \%$ ), disease free survival rate ( $42 \%$ vs. $20 \%$ ) and local control (66\% vs. $42 \%$ ) were significantly better than radiotherapy alone arm. Hematologic toxicity and oral mucositis (71\% vs. $39 \%$ ) were also raised in concurrent chemo radiation group compared to radiotherapy alone (44).

In another phase III clinical trial known as RTOG 91-11, preservation of larynx was evaluated (46). Patients with stage III and IV laryngeal squamous cell carcinoma were randomly assigned in three groups. Group 1 received induction chemotherapy with PF (Cisplatin $100 \mathrm{mg}$ / $\mathrm{m}^{2}$ day 1 plus 5FU $1000 \mathrm{mg} / \mathrm{m}^{2}$ per day for 5 days continuos intravenous infusion) followed by radiotherapy (70 Gy). Patients in this group who respond completely or partially after two cycles of induction chemotherapy received another more cycle of chemotherapy before starting of radiotherapy. Group 2 received concurrent chemotherapy (Cisplatin $100 \mathrm{mg} / \mathrm{m}^{2}$ on day 1, 22, and 43 of radiotherapy course) with radiotherapy (70 Gy), and 
the third group received radiotherapy alone. Five-year laryngectomy free survival (the primary end point of the study) was $44.6,46.6$, and $33.9 \%$ for induction, concurrent and radiotherapy alone respectively. Difference in laryngectomy free survival was significant between concurrent chemoradiation and radiotherapy alone ( $\mathrm{P}$ $=0.011$ ) and induction chemotherapy and radiotherapy alone $(P=0.011)$. Preservation of larynx was higher in concurrent chemoradioation compared to induction chemotherapy $(\mathrm{P}=0.0029)$ and radiotherapy alone $(\mathrm{P}=$ 0.0017). Although the overall survival rate was higher in induction chemotherapy patients, but this finding was not statistically significant (46).

In another study performed on 46 patients with piriform sinus cancer, concurrent chemoradiation had a profound improving effect on regional control and larynx preservation; and larynx was preserved in more than $50 \%$ of patients undergoing this modality program (35).

\subsection{Sequential Therapy RCT's}

Sequential therapy comprises of induction chemotherapy followed by concurrent chemoradiation, which may need surgery as a complementary treatment. Theoretically, this modality has the advantages of both methods; so that induction chemotherapy part of this program increases the response to local treatment, organ preservation, decrease distant metastases rate and enables the clinician to evaluate the response to treatment. The concurrent chemoradiation part improves the regional control, survival rate (1). Several phase II trials have been performed focusing on the sequential modality program (42-57).

One study performed in Michigan University applied the following protocol to the larynx cancer patients: induction chemotherapy with PF followed by response assessment and then based on response concurrent chemoradiation or surgery was performed for responder and non-responder respectively. Results were too much favorable; $62 \%$ of patients were disease-free with the affected organ preserved in a 2-year follow-up (49).

Consistent with previous study, another study was performed in Yale University. Advanced head and neck cancer patients received cisplatin as the induction Chemotherapy agent followed by concurrent chemoradiation. Complete response was observed in $67 \%$ of patients and survival rate without disease progression was estimated to be $60 \%$ in a 5 -year period (55). Another study in advanced larynx cancer patients showed that sequential therapy resulted in a $47 \%$ survival rate, disease-free survival rate of $78 \%$ and loco-regional control of $78 \%$ after a 5-year follow-up (50).

\subsection{RCT’s Focusing on Taxan-Based Protocols}

Third generation of chemotherapy studies focus on addition of a taxan to induction chemotherapy for improv- ing its efficacy. The primary objective of these studies was to apply a stronger induction regimen comparable to concurrent chemoradiation which also has fewer complications compared to the latter modality. Table 3 shows the result of these studies (54-66). To evaluate the efficacy of induction chemotherapy regimen including paclitaxel, cisplatin and 5-FU, four studies were conducted by Dana Farber Institute (54-57).

Hitt et al. in 2002 compared sequential concurrent chemoradiation with two induction Chemotherapy protocols: paclitaxel + cisplatin vs. cisplatin +5 -FU. At the end of treatments, overall response rate was $98 \%$ and $88 \%$ respectively. Survival rate was higher on non-surgical patients receiving $\operatorname{taxan}(58)$.

In Phase III trial TAX323, induction regimen of TPF (docetaxel and cisplatin, day 1 ; fluorouracil by continuous infusion, days 1 to 5 ) was compared with PF regimen every 3 weeks for four cycles. Patients without progression of disease received radiotherapy alone within 4 to 7 weeks after completing chemotherapy. Progression free and overall survival rates were significantly higher in TPF group (59). Next study which followed TAX323 entitled TAX324 evaluated the same regimens for induction chemotherapy, but unlike TAX323, concurrent chemoradiation with weekly carboplatin was prescribed after induction chemotherapy. TPF receiving patients had better overall survival (the median overall survival 71 months vs. 30 months in PF group $(\mathrm{P}=0.006))$; better locoregional control $(\mathrm{P}=0.04)$. Neutropenia grade 3 or 4 was observed more in TPF group and thrombocytopenia combined with anemia was observed to a bigger extent in the second group of study (60).

Induction chemotherapy with paclitaxel and carboplatin followed by concurrent chemoradiation with paclitaxel was administered in head and neck cancer patients in a phase II trial. Larynx preservation after two years was favorable in oropharynx cancer patients (84\%), while being unfavorable in larynx cancer patients (74\%) (12).

\subsection{Meta-Analysis Studies}

A meta-analysis of chemotherapy on head and neck cancer by MACH-NC collaborative group revealed that induction chemotherapy before surgery or Radiotherapy has no positive impact on loco-regional treatment results, but subgroup analysis showed that induction Chemotherapy regimen including cisplatin and 5-FU (PF) has a $5 \%$ increment of survival rate in a 5 -year follow-up, while such an increase was not observed in carboplatin group. Addition of chemotherapy to radiotherapy in all stages of disease results in $8 \%$ improvement in 5-year survival rate. Eighty four RCT studies were analyzed in this study and it was demonstrated that this improvement in survival is observed in all regions of head and neck (oropharynx, larynx, hypopharynx, and oral cavity) and the main rationale for this 
increased survival is the reduction of local recurrence due to the effect of chemotherapy (67).

Another meta-analysis performed on 42 RCT's revealed that adding chemotherapy to the local definitive treatment increases complications, response rate and local control of the tumor.

A slight improvement about $4 \%$ in survival rate was observed (50\% against 54\%), but in studies using concomitant chemoradiation this improvement was noticeable (50\% vs. 58\%). Concomitant treatment reduced mortality up to $22 \%$ (8 - 33\%, 95\% C.I.) (68). In another meta-analysis study, eight RCT's addressing efficacy of induction therapy with PF and local treatment alone were evaluated. Induction Therapy had no effect on loco-regional control, but it significantly reduced metastasis and increased survival rate, though this increase was very slight (69). Results of the other three meta-analysis showed that survival rate is increased very scarce in chemotherapy modality $(2.8,4$, and $6.5 \%)$. Improved survival was just observed in studies applying concomitant chemoradiation (68).

Table 1. Randomized Clinical Trials on the Efficacy of Induction Chemotherapy on Survival Rate of Advanced Head and Neck Cancer Patients ${ }^{\text {a }}$

\begin{tabular}{|c|c|c|c|}
\hline Study & Chemotherapy Regimen & No. of Patients & Survival \\
\hline Stell et al. (1983) (22) & MTX + F or Urea + MP + CTX & 86 & No effect \\
\hline Toohill et al. (1987) (23) & $\mathrm{PF}$ & 60 & No effect \\
\hline Martin et al. (1990) (24) & $\mathrm{PF}$ & 75 & No effect \\
\hline Richard et al. (1991) (25) & VB & 222 & Improved \\
\hline Jaulerry et al. (1992) (26) & PVB & 100 & No effect \\
\hline Paccagnella et al. (1994) (7) & $\mathrm{PF}$ & 237 & Improved \\
\hline Athanasiadis et al.(1997) (27) & $\mathrm{PF}$ & 71 & No effect \\
\hline Domenge et al. $(2000)(6)$ & PF & 240 & No effect \\
\hline
\end{tabular}

${ }^{\text {a }}$ Abbreviations: CTX, cytoxan; F, 5-fu; M, mercaptopurin; MTX, methotroxat; VB, vincristin + bleomycin.

Table 2. Randomized Clinical Trials Comparing the Concomitant Radio Chemotherapy vs. Radiotherapy in Head and Neck Cancers a

\begin{tabular}{|c|c|c|c|c|}
\hline Study & Survival (P value) & Regional Control (Pvalue) & Chemotherapy Regimen & No. of Patients \\
\hline Merlano et al. (1992) (42) & $24 \%$ vs. $1 \%$ ( 00.01$)$ & $64 \%$ vs. $32 \%(0.03)$ & $\mathrm{PF}$ & 157 \\
\hline Wendt et al. (1998) (43) & $48 \%$ vs. $24 \%(0.003)$ & $36 \%$ vs. $17 \%(0.004)$ & $\mathrm{PF}$ & 270 \\
\hline Brizel et al. (1998)(29) & $55 \%$ vs. $37 \%(0.07)$ & $70 \%$ vs. $44 \%(0.01)$ & $\mathrm{PF}$ & 116 \\
\hline Calais et al. (1999) (44) & $51 \%$ vs. $31 \%(0.02)$ & $66 \%$ vs. $42 \%(0.03)$ & $\mathrm{CF}$ & 226 \\
\hline Adelstein et al. (2000) (45) & $37 \%$ vs. $20 \%(0.01)$ & & $\mathrm{PF}$ & 295 \\
\hline Denis et al. (2004) (5) & $48 \%$ vs. $25 \%(0.002)$ & $22 \%$ vs. $16 \%(0.05)$ & $\mathrm{CF}$ & 226 \\
\hline Forastiere et al. (2006) (46) & & & $\mathrm{PF}$ & 547 \\
\hline
\end{tabular}

a Abbreviations: CF, carboplatin + 5-Fu; PF, cisplatin + 5-Fu. 
Table 3. Studies on the Efficacy of Taxan-Based Induction Regimens in Head and Neck Cancer Patients a

\begin{tabular}{|c|c|c|c|c|}
\hline Study & 2-Year Survival ${ }^{\text {b }}$ & Response Rate ${ }^{\mathrm{b}}$ & Regimen & No. of Patients \\
\hline Posner et al. (2001) (57) & 79 & 93 & $\mathrm{TPF} \rightarrow \mathrm{RT}$ & 43 \\
\hline Colevas et al. (2002) (55) & 68 & 94 & $\mathrm{TPF} \rightarrow \mathrm{RT}$ & 34 \\
\hline Watanabe et al. (2003) (66) & 41 & 88 & $\mathrm{TPF} \rightarrow \mathrm{RT}$ & 48 \\
\hline Tsukuda et al. (2004)(65) & & 94 & $\mathrm{TPF} \rightarrow \mathrm{RT}$ & 18 \\
\hline Schrijvers et al.(2004) (64) & 93 & 71 & $\mathrm{TPF} \rightarrow \mathrm{RT}$ & 34 \\
\hline Cmelak et al. (2007)(12) & 76 & & $\mathrm{PC} \rightarrow \mathrm{PC}+\mathrm{RT}$ & 111 \\
\hline \multirow[t]{3}{*}{ Vermorken et al. (2007); Tax323 (59) } & & & & 358 \\
\hline & 43 & 72 & $\mathrm{TPF} \rightarrow \mathrm{RT}$ & \\
\hline & 32 & 59 & Or $: \mathrm{PF} \rightarrow \mathrm{RT}$ & \\
\hline \multirow[t]{3}{*}{ Posner et al. (2007); TAX324 (60) } & & & & 501 \\
\hline & 67 & 72 & $\mathrm{TPF} \rightarrow \mathrm{RT}+\mathrm{C}$ & \\
\hline & 55 & 64 & Or: $\mathrm{PF} \rightarrow \mathrm{RT}+\mathrm{P}$ & \\
\hline \multirow[t]{3}{*}{ Pointreau et al. (2009) (61) } & & & & 213 \\
\hline & 73 & 80 & $\mathrm{TPF} \rightarrow \mathrm{RT}$ & \\
\hline & 72 & 59.2 & Or: $\mathrm{PF} \rightarrow \mathrm{RT}$ & \\
\hline Larizadeh et al. (2010) (62) & 83 & 85.5 & $\mathrm{TPF} \rightarrow \mathrm{RT}$ & 76 \\
\hline
\end{tabular}

a Abbreviations: C, carboplatin; PC, paclitaxol + carboplatin; RT, radiotherapy; TPF, docetaxel + cisplatin + 5-Fu.

$\mathrm{b}$ Data are presented as \%.

\section{Results}

More than 3 decades is past from the commencement of studies on chemotherapy treatment effect on head and neck cancers. Studies have shown that chemotherapy can increase primary response to treatment and can be beneficial in organ preservation to some extent, but its role in improvement of survival rate and the best treatment protocol is not clearly defined yet (1). Review of the literature shows that inadequate number of patients, different protocols and regimens complicate the procedure of making an ultimate decision. Another reason for different and sometimes controversial results might be the heterogenic nature of head and neck cancers and the effect of other factors such as e-Cadherin gene expression in these cancers (70).

The following results can be obtained from induction studies:

-Induction chemotherapy has a response rate of up to $80-90 \%$. This finding can be of clinical importance, so that by limiting local treatment (surgery or radiotherapy), patients experience lesser disabilities induced from local treatments (14).

-According to Warden's study, response to induction Chemotherapy can predict future response to Radiotherapy. This default can be considered for selection of ultimate modality. Patients responding to induction treatment can be treated with oragan-preservation based modalities such as radiotherapy. Those who do not respond well to chemotherapy are not a good candidate for cadiotherapy and should undergo radical dissection. Although radiotherapy is not recommended for these patients, but some researchers believe that concomitant Radiochemotherapy can be of benefits in patients not responding to induction therapy (16-18).

- Induction chemotherapy will ultimately increase organ preservation and quality of life (19).

- Though the effect of induction Chemotherapy on increasing survival rate is not proved yet, but it is noticeable that this modality has no negative impact on survival rate; so in cases which organ preservation is one of the primary objectives, this protocol can be used before local treatments in advanced local tumors (20-22).

Due to the inefficacy of induction chemotherapy on inducing a profound impact of survival rate, second generation of studies was designed so that concomitant therapy was used as the sensitizing procedure for radiotherapy to improve local control of tumor. Recent RCT's and meta-analysis have demonstrated that concomitant Radiochemotherapy is more effective in improvement of survival rate and local control compared to induction Chemotherapy. Due to the more extended complications, these modalities are the modality of choice in patients whom are generally healthy (32, 40-44), (45-51), (52-58), (59-65), (66-72).

Meta-analysis studies have shown the following results: - Induction Chemotherapy does not increase survival rate, - Induction chemotherapy with cisplatin results in a 5\% increase in survival rate,

- Radiochemotherapy concomitant regimens have an $8 \%$ increased surveillance (67-69). 
Sequential therapies comprising induction chemotherapy and concomitant radiochemotherapy were introduced to aggregate the possible benefits of both modalities and seem to be an appropriate method in treating head and neck cancers. Early commencement of systemic treatments which results in removal of hidden metastatic sites and simultaneous application of radiotherapy with chemotherapy improves the chance of local treatment in this modality program (62).

Third generation of studies consisting taxan-based regimens were formed to improve the efficacy of induction chemotherapy. Results of these studies revealed that adding taxan to PF regimen leads to improved outcomes, but the question that whether TPF regimen as induction chemotherapy can be equal to concomitant chemotherapy or not still remains (54-60). There are some other ongoing phase III trials in which the efficacy of taxan-based regimens is compared to concomitant radiochemotherapy.

\section{Conclusions}

Phase III clinical trials will reveal that which of concomitant radiochemotherapy or sequential therapy is of clinical benefit to the patients. Till that time, sequential therapies based on TPF can be an acceptable alternative for concomitant radiochemotherapy in advanced head and neck cancers.

\section{Authors' Contributions}

Mohammad Hassan Larizadeh is the archival author and attests to the integrity of the original data and the analysis reported in this manuscript. Dr. Larizadeh also attests to approving the final manuscript.

\section{Funding/Support}

This research was approved and supported by a grant (K/13-91) from Kerman Neuroscience Research Center.

\section{References}

1. Posner M. Evolving strategies for combined-modality therapy for locally advanced head and neck cancer. Oncologist. 2007;12(8):967-74.

2. Posner MR. Paradigm shift in the treatment of head and neck cancer: the role of neoadjuvant chemotherapy. Oncologist 2005;10 Suppl 3:11-9.

3. Posner MR, Haddad RI, Wirth L, Norris CM, Goguen LA, Mahadevan $\mathrm{A}$, et al. Induction chemotherapy in locally advanced squamous cell cancer of the head and neck: evolution of the sequential treatment approach. Semin Oncol. 2004;31(6):778-85.

4. Induction chemotherapy plus radiation compared with surgery plus radiation in patients with advanced laryngeal cancer. The Department of Veterans Affairs Laryngeal Cancer Study Group. $N$ EnglJ Med. 1991;324(24):1685-90.

5. Denis F, Garaud P, Bardet E, Alfonsi M, Sire C, Germain T, et al. Final results of the 94-01 French Head and Neck Oncology and Radiotherapy Group randomized trial comparing radiotherapy alone with concomitant radiochemotherapy in advanced-stage oropharynx carcinoma. J Clin Oncol. 2004;22(1):69-76.

6. Domenge C, Hill C, Lefebvre JL, De Raucourt D, Rhein B, Wibault $\mathrm{P}$, et al. Randomized trial of neoadjuvant chemotherapy in oro- pharyngeal carcinoma. French Groupe d'Etude des Tumeurs de la Tete et du Cou (GETTEC). Br J Cancer. 2000;83(12):1594-8.

7. Paccagnella A, Orlando A, Marchiori C, Zorat PL, Cavaniglia G, Sileni VC, et al. Phase III trial of initial chemotherapy in stage III or IV head and neck cancers: a study by the Gruppo di Studio sui Tumori della Testa e del Collo. J Natl Cancer Inst. 1994;86 (4):265-72.

8. Lefebvre JL, Chevalier D, Luboinski B, Kirkpatrick A, Collette L, Sahmoud T. Larynx preservation in pyriform sinus cancer: preliminary results of a European Organization for Research and Treatment of Cancer phase III trial. EORTC Head and Neck Cancer Cooperative Group.J Natl Cancer Inst. 1996;88(13):890-9.

9. Forastiere AA, Goepfert H, Maor M, Pajak TF, Weber R, Morrison W, et al. Concurrent chemotherapy and radiotherapy for organ preservation in advanced laryngeal cancer. $N$ Engl J Med. 2003;349(22):2091-8.

10. Semrau S, Waldfahrer F, Lell M, Linke R, Klautke G, Kuwert T, et al. Feasibility, toxicity, and efficacy of short induction chemotherapy of docetaxel plus cisplatin or carboplatin (TP) followed by concurrent chemoradio-therapy for organ preservation in advanced cancer of the hypopharynx, larynx, and base of tongue. Early results. Strahlenther Onkol. 2011;187(1):15-22.

11. Richard JM, Sancho-Garnier H, Pessey JJ, Luboinski B, Lefebvre JL, Dehesdin D, et al. Randomized trial of induction chemotherapy in larynx carcinoma. Oral Oncol. 1998;34(3):224-8.

12. Cmelak AJ, Li S, Goldwasser MA, Murphy B, Cannon M, Pinto H, et al. Phase II trial of chemoradiation for organ preservation in resectable stage III or IV squamous cell carcinomas of the larynx or oropharynx: results of Eastern Cooperative Oncology Group Study E2399. J Clin Oncol. 2007;25(25):3971-7.

13. Bourhis J, Guigay J, Temam S, Pignon JP. Chemo-radiotherapy in head and neck cancer. Ann Oncol. 2006;17 Suppl 10:x39-41.

14. Adelstein DJ. Induction chemotherapy in head and neck cancer Hematol Oncol Clin North Am. 1999;13(4):689-98.

15. Cohen EE, Lingen MW, Vokes EE. The expanding role of systemic therapy in head and neck cancer.J Clin Oncol. 2004;22(9):1743-52.

16. Kies MS. Induction chemotherapy for squamous cancer of the head and neck. Curr Oncol Rep. 2007;9(2):129-33.

17. Adelstein DJ. Redefining the role of induction chemotherapy in head and neck cancer.J Clin Oncol. 2008;26(19):3117-9.

18. Forastiere A, Koch W, Trotti A, Sidransky D. Head and neck cancer. N Engl J Med. 2001;345(26):1890-900.

19. Majem M, Mesia R, Manos M, Gomez J, Galiana R, Cardenal F, et al Does induction chemotherapy still have a role in larynx preservation strategies? The experience of Institut Catala d'Oncologia in stage III larynx carcinoma. Laryngoscope. 2006;116(9):1651-6.

20. Hitt R. Induction Chemotherapy in head and neck cancer. Annal Oncol. 2006;17(Supplement 10):42-4.

21. Salvajoli JV, Morioka H, Trippe N, Kowalski LP. A randomized trial of neoadjuvant vs concomitant chemotherapy vs radiotherapy alone in the treatment of stage IV head and neck squamous cell carcinoma. Eur Arch Otorhinolaryngol. 1992;249(4):211-5.

22. Stell PM, Dalby JE, Strickland P, Fraser JG, Bradley PJ, Flood LM. Sequential chemotherapy and radiotherapy in advanced head and neck cancer. Clin Radiol. 1983;34(4):463-7.

23. Toohill RJ, Anderson T, Byhardt RW, Cox JD, Duncavage JA, Grossman TW, et al. Cisplatin and fluorouracil as neoadjuvant therapy in head and neck cancer. A preliminary report. Arch Otolaryngol Head Neck Surg. 1987;113(7):758-61.

24. Martin M, Hazan A, Vergnes L, Peytral C, Mazeron JJ, Senechaut JP, et al. Randomized study of 5 fluorouracil and cis platin as neoadjuvant therapy in head and neck cancer: a preliminary report. Int J Radiat Oncol Biol Phys. 1990;19(4):973-5.

25. Richard JM, Kramar A, Molinari R, Lefebvre JL, Blanchet F, Jortay A, et al. Randomised EORTC head and neck cooperative group trial of preoperative intra-arterial chemotherapy in oral cavity and oropharynx carcinoma. Eur J Cancer. 1991;27(7):821-7.

26. Jaulerry C, Rodriguez J, Brunin F, Jouve M, Mosseri V, Point D, et al. Induction chemotherapy in advanced head and neck tumors: results of two randomized trials. Int J Radiat Oncol Biol Phys. 1992;23(3):483-9.

27. Athanasiadis I, Taylor S, Vokes EE, Pelzer HJ, Rademaker A, Mittal $\mathrm{BB}$, et al. Phase II study of induction and adjuvant chemotherapy 
for squamous cell carcinoma of the head and neck. A long-term analysis for the Illinois Cancer Center. Cancer. 1997;79(3):588-94.

28. Volling P, Schroder M, Eckel H, Ebeling O, Stennert E. [Results of a prospective randomized trial with induction chemotherapy for cancer of the oral cavity and tonsils]. HNO. 1999;47(10):899-906.

29. Brizel DM, Albers ME, Fisher SR, Scher RL, Richtsmeier WJ, Hars V, et al. Hyperfractionated irradiation with or without concurrent chemotherapy for locally advanced head and neck cancer. $N$ Engl JMed. 1998;338(25):1798-804.

30. Adelstein DJ, Li Y, Adams GL, Wagner HJ, Kish JA, Ensley JF, et al. An intergroup phase III comparison of standard radiation therapy and two schedules of concurrent chemoradiotherapy in patients with unresectable squamous cell head and neck cancer. $J$ Clin Oncol. 2003;21(1):92-8.

31. Coughlin CT, Richmond RC. Biologic and clinical developments of cisplatin combined with radiation: concepts, utility, projections for new trials, and the emergence of carboplatin. Semin Oncol. 1989;16(4 Suppl 6):31-43.

32. Vokes EE, Weichselbaum RR. Concomitant chemoradiotherapy: rationale and clinical experience in patients with solid tumors. $J$ Clin Oncol. 1990;8(5):911-34.

33. Schnabel T, Zamboglou N, Kolotas C, Hartmann A, Schmitt G. Combined radiochemotherapy with carboplatin in the treatment of advanced head and neck carcinomas. Oncology. 1993;50 Suppl 2:16-22.

34. Argiris A, Haraf DJ, Kies MS, Vokes EE. Intensive concurrent chemoradiotherapy for head and neck cancer with 5-Fluorouracil- and hydroxyurea-based regimens: reversing a pattern of failure. Oncologist. 2003;8(4):350-60.

35. Prades JM, Schmitt TM, Timoshenko AP, Simon PG, de Cornulier J, Durand M, et al. Concomitant chemoradiotherapy in pyriform sinus carcinoma. Arch Otolaryngol Head Neck Surg. 2002;128(4):384-8.

36. Vokes EE, Kies MS, Haraf DJ, Stenson K, List M, Humerickhouse $\mathrm{R}$, et al. Concomitant chemoradiotherapy as primary therapy for locoregionally advanced head and neck cancer. J Clin Oncol. 2000;18(8):1652-61.

37. Bernier J, Cooper JS. Chemoradiation after surgery for high-risk head and neck cancer patients: how strong is the evidence? Oncologist. 2005;10(3):215-24.

38. Adelstein DJ, Saxton JP, Lavertu P, Rybicki LA, Esclamado RM, Wood BG, et al. Maximizing local control and organ preservation in stage IV squamous cell head and neck cancer With hyperfractionated radiation and concurrent chemotherapy. J Clin Oncol. 2002;20(5):1405-10.

39. Cooper JS, Ang KK. Concomitant chemotherapy and radiation therapy certainly improves local control. Int J Radiat Oncol Biol Phys. 2005;61(1):7-9.

40. Tannock IF. Combined modality treatment with radiotherapy and chemotherapy. Radiother Oncol. 1989;16(2):83-101.

41. Mosallaee A, Larizadeh MH, Saalabian MJ, Ahmady Kohanali J Study of the role of combined radiotherapy \& Chemotherapy in treatment of squamous cell tumors of head and neck. J Res Med Sci. 2003;8(4):88-5.

42. Merlano M, Vitale V, Rosso R, Benasso M, Corvo R, Cavallari M, et al. Treatment of advanced squamous-cell carcinoma of the head and neck with alternating chemotherapy and radiotherapy. $N$ Engl J Med.1992;327(16):1115-21.

43. Wendt TG, Grabenbauer GG, Rodel CM, Thiel HJ, Aydin H, Rohloff $\mathrm{R}$, et al. Simultaneous radiochemotherapy versus radiotherapy alone in advanced head and neck cancer: a randomized multicenter study. J Clin Oncol. 1998;16(4):1318-24.

44. Calais G, Alfonsi M, Bardet E, Sire C, Germain T, Bergerot P, et al Randomized trial of radiation therapy versus concomitant chemotherapy and radiation therapy for advanced-stage oropharynx carcinoma. J Natl Cancer Inst. 1999;91(24):2081-6.

45. Adelstein DJ, Lavertu P, Saxton JP, Secic M, Wood BG, Wanamaker JR, et al. Mature results of a phase III randomized trial comparing concurrent chemoradiotherapy with radiation therapy alone in patients with stage III and IV squamous cell carcinoma of the head and neck. Cancer. 2000;88(4):876-83.

46. Forastiere AA, Maor M, Weber RS, Pajak T, Glisson B, Trotti A, et al. Long-term results of Intergroup RTOG 91-11: A phase III trial to preserve the larynx--Induction cisplatin/5-FU and radiation therapy versus concurrent cisplatin and radiation therapy versus radiation therapy.J Clin Oncol. 2006;24(18_suppl):284.

47. Vokes EE, Weichselbaum RR, Mick R, McEvilly JM, Haraf DJ, Panje WR. Favorable long-term survival following induction chemotherapy with cisplatin, fluorouracil, and leucovorin and concomitant chemoradiotherapy for locally advanced head and neck cancer. J Natl Cancer Inst. 1992;84(11):877-82.

48. Vokes EE, Kies M, Haraf DJ, Mick R, Moran WJ, Kozloff M, et al Induction chemotherapy followed by concomitant chemoradiotherapy for advanced head and neck cancer: impact on the natural history of the disease.J Clin Oncol. 1995;13(4):876-83.

49. Urba S, Wolf G, Bradford C. Improved survival and decreased late salvage surgery using chemo-selection of patients for organ preservation in advanced laryngeal cancer. Proc Am Soc Clin Oncol. 2003;22(1):497.

50. Mantz CA, Vokes EE, Kies MS, Mittal B, Witt ME, List MA, et al. Sequential induction chemotherapy and concomitant chemoradiotherapy in the management of locoregionally advanced laryngeal cancer. Ann Oncol. 2001;12(3):343-7.

51. Lefebvre JL, Rolland F, Tesselaar M, Bardet E, Leemans CR, Geoffrois L, et al. Phase 3 randomized trial on larynx preservation comparing sequential vs alternating chemotherapy and radiotherapy.J Natl Cancer Inst. 2009;101(3):142-52.

52. Kies MS, Haraf DJ, Athanasiadis I, Kozloff M, Mittal B, Pelzer H, et al. Induction chemotherapy followed by concurrent chemoradiation for advanced head and neck cancer: improved disease control and survival.J Clin Oncol. 1998;16(8):2715-21.

53. Psyrri A, Kwong M, DiStasio S, Lekakis L, Kassar M, Sasaki C, et al. Cisplatin, fluorouracil, and leucovorin induction chemotherapy followed by concurrent cisplatin chemoradiotherapy for organ preservation and cure in patients with advanced head and neck cancer: long-term follow-up. J Clin Oncol. 2004;22(15):3061-9.

54. Colevas AD, Norris CM, Tishler RB, Fried MP, Gomolin HI, Amrein $\mathrm{P}$, et al. Phase II trial of docetaxel, cisplatin, fluorouracil, and leucovorin as induction for squamous cell carcinoma of the head and neck.J Clin Oncol.1999;17(11):3503-11.

55. Colevas AD, Norris CM, Tishler RB, Lamb CC, Fried MP, Goguen LA, et al. Phase I/II trial of outpatient docetaxel, cisplatin, 5-fluorouracil, leucovorin (opTPFL) as induction for squamous cell carcADDIN EN.CITE.DATAinoma of the head and neck (SCCHN). Am J Clin Oncol. 2002;25(2):153-9.

56. Haddad R, Colevas AD, Tishler R, Busse P, Goguen L, Sullivan C, et al. Docetaxel, cisplatin, and 5-fluorouracil-based induction chemotherapy in patients with locally advanced squamous cell carcinoma of the head and neck: the Dana Farber Cancer Institute experience. Cancer. 2003;97(2):412-8.

57. Posner MR, Glisson B, Frenette G, Al-Sarraf M, Colevas AD, Norris $\mathrm{CM}$, et al. Multicenter phase I-II trial of docetaxel, cisplatin, and fluorouracil induction chemotherapy for patients with locally advanced squamous cell cancer of the head and neck.J Clin Oncol. 2001;19(4):1096-104.

58. Colevas AD, Norris CM, Tishler RB, Lamb CC, Fried MP, Goguen LA, et al. Phase I/II trial of outpatient docetaxel, cisplatin, 5-fluorouracil, leucovorin (opTPFL) as induction for squamous cell carcinoma of the head and neck (SCCHN). Am J Clin Oncol. 2002;25(2):153-9.

59. Hitt R, Paz-Ares L, Brandariz A, Castellano D, Pena C, Millan JM, et al. Induction chemotherapy with paclitaxel, cisplatin and 5-fluorouracil for squamous cell carcinoma of the head and neck: longterm results of a phase II trial. Ann Oncol. 2002;13(10):1665-73.

60. Vermorken JB, Remenar E, van Herpen C, Gorlia T, Mesia R, Degardin $\mathrm{M}$, et al. Cisplatin, fluorouracil, and docetaxel in unresectable head and neck cancer. NEngl J Med. 2007;357(17):1695-704.

61. Posner MR, Hershock DM, Blajman CR, Mickiewicz E, Winquist E, Gorbounova V, et al. Cisplatin and fluorouracil alone or with docetaxel in head and neck cancer. $N$ Engl J Med. 2007;357(17):1705-15.

62. Pignon JP, Bourhis J, Domenge C, Designe L. Chemotherapy added to locoregional treatment for head and neck squamouscell carcinoma: three meta-analyses of updated individual data. 
MACH-NC Collaborative Group. Meta-Analysis of Chemotherapy on Head and Neck Cancer. Lancet. 2000;355(9208):949-55.

63. El-Sayed S, Nelson N. Adjuvant and adjunctive chemotherapy in the management of squamous cell carcinoma of the head and neck region. A meta-analysis of prospective and randomized trials. J Clin Oncol. 1996;14(3):838-47.

64. Su YX, Zheng JW, Zheng GS, Liao GQ, Zhang ZY. Neoadjuvant chemotherapy of cisplatin and fluorouracil regimen in head and neck squamous cell carcinoma: a meta-analysis. Chin Med J (Engl). 2008;121(19):1939-44.

65. Watanabe A, Taniguchi M, Sasaki S. Induction chemotherapy with docetaxel, cisplatin, fluorouracil and l-leucovorin for locally advanced head and neck cancers: a modified regimen for Japanese patients. Anticancer Drugs. 2003;14(10):801-7.

66. Tsukuda M, Mikami Y, Tanigaki Y, Katori H, Horiuchi C, Ikeda Y, et al. Phase I trial of combined chemotherapy with docetaxel, cisplatin, and 5-fluorouracil for patients with locally advanced squamous cell carcinoma of the head and neck. Int J Clin Oncol. 2004;9(3):161-6.

67. Schrijvers D, Van Herpen C, Kerger J, Joosens E, Van Laer C, Awada
A, et al. Docetaxel, cisplatin and 5-fluorouracil in patients with locally advanced unresectable head and neck cancer: a phase I-II feasibility study. Ann Oncol. 2004;15(4):638-45.

68. Pointreau Y, Garaud P, Chapet S, Sire C, Tuchais C, Tortochaux J, et al. Randomized trial of induction chemotherapy with cisplatin and 5-fluorouracil with or without docetaxel for larynx preservation.J Natl Cancer Inst. 2009;101(7):498-506.

69. Larizadeh MH, Damghani MA. Sequential chemoradiotherapy in advanced laryngeal cancer: an institutional experience. Asia Pac JClin Oncol. 2010;6(2):106-10.

70. Larizadeh MH, Damghani MA. Expression of E-Cadherin in squamous cell carcinoma of the larynx and its correlation with clinicopathological features. J Med Sci. 2009;9(1):41-5.

71. Schrijvers D, Vermorken JB. Taxanes in the treatment of head and neck cancer. Curr Opin Oncol. 2005;17(3):218-24.

72. Gibson MK, Forastiere AA. Reassessment of the role of induc tion chemotherapy for head and neck cancer. Lancet Oncol. 2006;7(7):565-74.

73. Larizadeh MH, Nasirinejad Z. Radiotherapy for head and neck cancers: Indications and Techniques.Tehran: Vadiaat publications; 1388 . 